\title{
Baclofen pump catheter leakage after migration of the abdominal catheter in a pediatric patient with spasticity
}

\author{
Amer Dastgir, MD, Nathan J. Ranalli, MD, Theresa L. MacGregor, PhD, and Philipp R. Aldana, MD \\ Department of Neurosurgery, Division of Pediatric Neurosurgery, University of Florida College of Medicine-Jacksonville, Florida
}

The authors report an unusual case of intrathecal baclofen withdrawal due to the perforation and subsequent leakage of a baclofen pump catheter in a patient with spastic cerebral palsy. A 15-year-old boy underwent an uncomplicated placement of an intrathecal baclofen pump for the treatment of spasticity due to cerebral palsy. After excellent control of symptoms for 3 years, the patient presented to the emergency department with increasing tremors following a refill of his baclofen pump. Initial evaluation consisted of radiographs of the pump and catheter, which appeared normal, and a successful aspiration of CSF from the pump's side port. A CT dye study revealed a portion of the catheter directly overlying the refill port and extravasation of radiopaque dye into the subfascial pocket anterior to the pump. During subsequent revision surgery, a small puncture hole in the catheter was seen to be leaking the drug. The likely cause of the puncture was an inadvertent perforation of the catheter by a needle during the refilling of the pump. This case report highlights a unique complication in a patient with an intrathecal baclofen pump. Physicians caring for these patients should be aware of this rare yet potential complication in patients presenting with baclofen withdrawal symptoms.

http://thejns.org/doi/abs/10.3171/2015.2.PEDS14501

KEY WORDS baclofen pump; intrathecal; perforation; leakage; baclofen withdrawal; spasticity; catheter migration; functional neurosurgery

$\mathrm{B}$ ACLOFEN is an agonist for GABA B receptors and is mainly used in the treatment of spasticity. 15,20 It is an analog of $\gamma$-aminobutyric acid, which can inhibit the release of excitatory neurotransmitters in the central nervous system. ${ }^{7,30,39}$ Baclofen can be given orally or intrathecally through the use of an intrathecal pump, which uses a catheter placed in the spinal subarachnoid space. ${ }^{41}$ Intrathecal baclofen delivery via a surgically implanted pump placed in the abdomen began in the 1990s as a means of reducing spasticity due to cerebral palsy.

Intrathecal baclofen is far more effective than the oral version. In addition, many patients do not develop a significant tolerance to intrathecal baclofen. Even after years of continued usage, these patients still benefit from the drug's therapeutic antispasmodic effects. ${ }^{17}$ Discontinuation of baclofen can result in withdrawal symptoms, especially if the medication has been used continuously over a long period of time. These withdrawal symptoms can mimic alcohol or benzodiazepine withdrawal. Malfunction of the implanted pump or intrathecal catheter results in withdrawal. Symptoms can include but are not limited to dizzi- ness, disorientation, agitation, hypertonia, spasticity, rigidity, and seizures. Baclofen withdrawal symptoms can be minimized by tapering down the medication. ${ }^{27}$ Malfunction of the pump hardware and catheter $(21 \%-33 \%)$ and infection $(9 \%-10 \%)$ are the most common complications in patients. Catheter-related problems are the most common cause of hardware malfunction. . $^{5,8,8,16,44}$

\section{Case Report}

History and Examination

This 15-year-old male patient with a history of cerebral palsy had an intrathecal baclofen pump implanted almost 3 years previously for the management of spasticity. He presented to the emergency department with a history of increasing tremors 2 days after the refill of his baclofen pump. The patient's mother reported tremors in his right leg with progression to the other leg and both arms. Physical examination revealed generalized tremors in all extremities increasing with movement.

Plain radiographs suggested a normal-appearing pump

SUBMITTED September 23, 2014. ACCEPTED February 20, 2015.

INCLUDE WHEN CITING Published online June 5, 2015; DOI: 10.3171/2015.2.PEDS14501.

DISCLOSURE The authors report no conflict of interest concerning the materials or methods used in this study or the findings specified in this paper. 
and intact catheter. Subsequently, the side port of the baclofen pump was accessed, and $2 \mathrm{ml}$ of clear CSF was aspirated. A CT dye study revealed extravasation of radiopaque dye into the subfascial pocket surrounding the pump, with a portion of the catheter seen directly overlying the pump refill port (Fig. 1). The patient was brought into the operating room for exploration and revision of the pump and catheter.

\section{Operation}

The patient was taken to the operating room and placed under general anesthesia. The abdominal baclofen pump and catheter were surgically dissected. The pump tubing was found to cross directly over the refill reservoir of the pump and had an active leakage of the drug from a small puncture hole in the pump catheter just proximal to the straight connector (Fig. 2). The pump was removed, and the leaking segment of the catheter along with a few centimeters of proximal and distal tubing were removed and replaced. The pump was then reimplanted with the catheter positioned posterior to the pump.

\section{Postoperative Course}

Postoperatively, the patient experienced a reduction in baclofen withdrawal symptoms including spasticity, and he returned to his clinical baseline. The patient was discharged home 48 hours later in good condition.

\section{Literature Review}

We performed a literature search using PubMed and the search terms "baclofen pump catheter" "baclofen pump catheter malfunction," "baclofen pump catheter leakage," and "baclofen pump case report." There were no language exclusions. To include any relevant publications, additional studies were traced by checking the reference lists of selected articles.

\section{Discussion}

This case report highlights a previously unreported

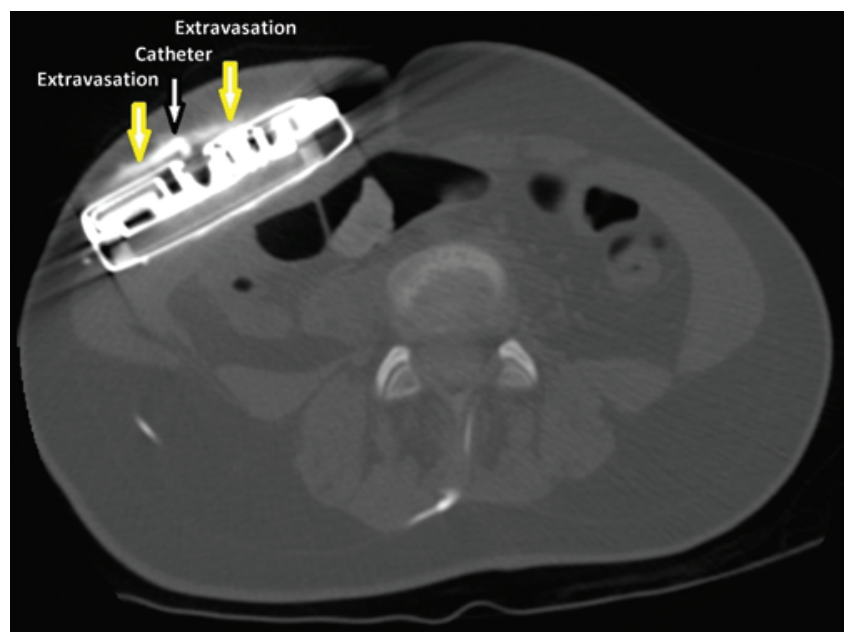

FIG. 1. Axial postcontrast CT scan of the abdomen demonstrating intrathecal baclofen pump with extravasation of radiopaque dye into the subfascial compartment anterior to the pump; the catheter is seen directly overlying the refill port. Figure is available in color online only.

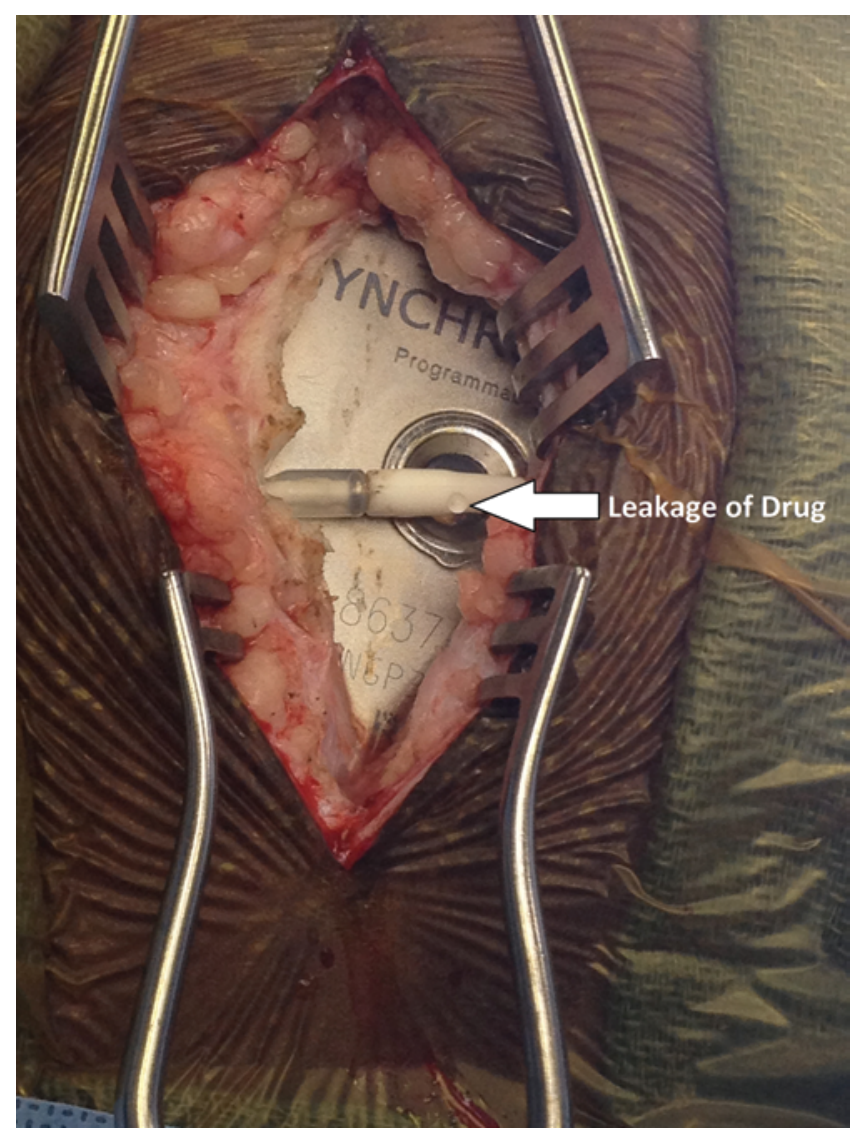

FIG. 2. Intraoperative picture of the intrathecal baclofen pump with the pump catheter crossing over the refill reservoir of the pump. Leakage of the drug can be seen from a small hole in the catheter. Figure is available in color online only.

complication of a baclofen catheter perforation during pump refill causing acute baclofen withdrawal in a patient.

Intrathecal baclofen is commonly used to treat spasticity, resulting in a better quality of life for patients., ${ }^{1,2,9}$ $11,23,24,26,33,43$ Although it has been very effective in treating spasticity, the therapy does entail certain risks, ${ }^{4,14,21,22}$ with approximately $25 \%-30 \%$ of patients experiencing a complication. ${ }^{4,22-24}$ These complications can be from dosing (overdose or underdose), mechanical failure of the pump or catheter, and infection of the hardware or local tissues. ${ }^{414,21,22,44}$ Infections, leakage of CSF, and catheterrelated issues are the most common complications. ${ }^{1,33,44,45}$ In patients on intrathecal baclofen, withdrawal symptoms can occur when the medication dosage is decreased or abruptly stopped. $3,6,10,11,14,19-22,25,31,32,37,40,47$ Watve et al. observed that intrathecal baclofen withdrawal is frequently due to catheter malfunction. ${ }^{46}$ Baclofen withdrawal can be characterized by reflex spasticity, seizures, central nervous system depression, and hyperthermia, which may progress to disseminated intravascular coagulation and organ failure if left untreated. $3,10,14,20,21,25,32,47$ Baclofen withdrawal symptoms can begin within the first 3 days after slowing or stopping the medication, whether orally or intrathecally. ${ }^{10,29,38,39,46,47}$ These symptoms are likely caused by the removal of the inhibitory tone on the GABA B receptors. ${ }^{10,38,46}$ 
Catheter-related complications are the most common type of complication associated with intrathecal baclofen pumps. ${ }^{34,35}$ Catheter complications have numerous etiologies, including breakage, dislodgment, kinks, fibrous blockages, and intraoperative iatrogenic nicks. ${ }^{9,34-37}$ Taira et al. reported that of 400 patients who underwent placement of an intrathecal baclofen pump in Japan between 2005 and 2011, 6 (1.5\%) of them had a breakage in the pump catheter..$^{42}$ In another study, 4 of 119 pediatric patients $(3 \%)$ in the same hospital with an intrathecal baclofen pump suffered a catheter break..$^{18}$ Dickerman et al. reported that out of 110 patients at their institution with an intrathecal baclofen pump, 3 (2.7\%) required a revision of the pump due to a catheter breakage. ${ }^{13}$ Dickerman and Schneider, in a separate paper, observed a catheter break in the pump catheter neck in one of their patients, on 2 separate occasions 6 months apart. ${ }^{12}$ The catheter neck was found to be lying over the iliac crest during both surgeries in this patient, which led the authors to conclude that repetitive compression against the iliac crest was the source of the catheter break. ${ }^{12}$ However, to the best of our knowledge there is no documented case of the perforation of an intrathecal pump catheter during the medicationrefilling process.

Although many causes must be considered in the differential diagnosis of baclofen withdrawal, pump catheter malfunction must be given ample consideration. In our case, the location of the catheter directly overlying the refill port predisposed it to needle puncture during the refill process. Although the catheter was not positioned there during the original implantation, it somehow migrated over time. Having prior knowledge of this to inform the staff performing the pump refill would have been useful, but we are not sure if this complication would have been permanently avoided given the need for repeated refills. In general, radiography or CT imaging can be performed on a routine basis to check for catheter migration, in particular near the port of the pump, prior to refill. However, given the rarity of the complication documented in this case report and the long-term risks of radiation exposure in childhood, we do not recommend it. This case does illustrate the utility of a CT dye study in the evaluation of a patient with a baclofen pump exhibiting withdrawal symptoms, following negative radiographs and pump side port aspirations.

The technique used during this particular refill was similar to that in previous refills. The patient was placed supine for the procedure, the abdominal region was exposed, and the pump was checked electronically. The area was then cleaned with an antiseptic solution, and the site was isolated for sterility using a drape. A 22-gauge needle was inserted into the refill port of the pump located in the center of the device. Any old remaining medication was drawn out, and the new medication was injected. After removing the needle, a dressing was applied to the puncture site. Finally, the pump was reprogrammed. There was no "rolling" feeling or anything else out of the ordinary during the refilling process. Multiple punctures were not required. In general, baclofen pump refills are performed every 1-6 months depending on the dosage of the drug, concentration of the drug, and size of the pump that the individual patient had implanted. This modality of treatment is flexible in that the rate of intrathecal infusion can be automatically adjusted throughout the day. Refills are scheduled based on calculations made by the programming device, as was the case for our patient. Baclofen tends to break down if left in the pump for longer than 6 months. Our patient received his refills approximately every 3 months, as was the case with this particular refill.

We theorize that the abdominal catheter migrated from the time of insertion to the time of inadvertent puncture. Although there is not a previous CT scan, the immediate postoperative radiograph from 2012 (Fig. 3) and the scout radiograph from a preoperative $\mathrm{CT}$ performed prior to the catheter revision in 2014 (Fig. 4) show the pump in a stable position but with repositioning of the tubing from behind the pump in 2012 to the front of the pump in 2014 . Although there is not a formal algorithm documented in the literature, we recommend simple palpation for the presence of the catheter over the refill port by the individual refilling the pump prior to insertion of the needle. The health care provider doing this should pay particular attention to the possibility of the catheter migrating. In the event that the tubing is suspected to be over the refill port or the tubing is palpable anterior to the pump, imaging studies, such as screening anteroposterior and lateral radiographs, are warranted.

\section{Conclusions}

This case illustrates the need for physicians treating patients using an intrathecal baclofen pump to be vigilant in considering all possible causes of baclofen withdrawal symptoms in their patients. Surgeons placing these pumps could consider leaving a smaller length of catheter in the abdominal compartment behind the pump to reduce the

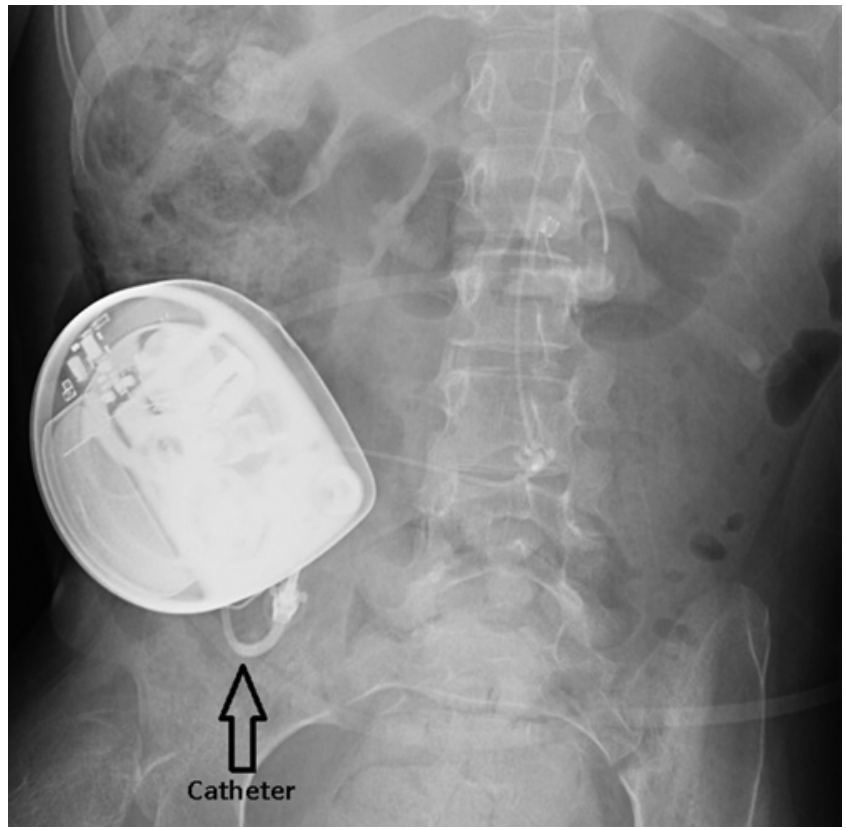

FIG. 3. Immediate postoperative kidney, ureter, and bladder (KUB) radiograph obtained on September 13, 2012, after insertion of the pump. There is no evidence of the catheter anterior to the abdominal pump. 


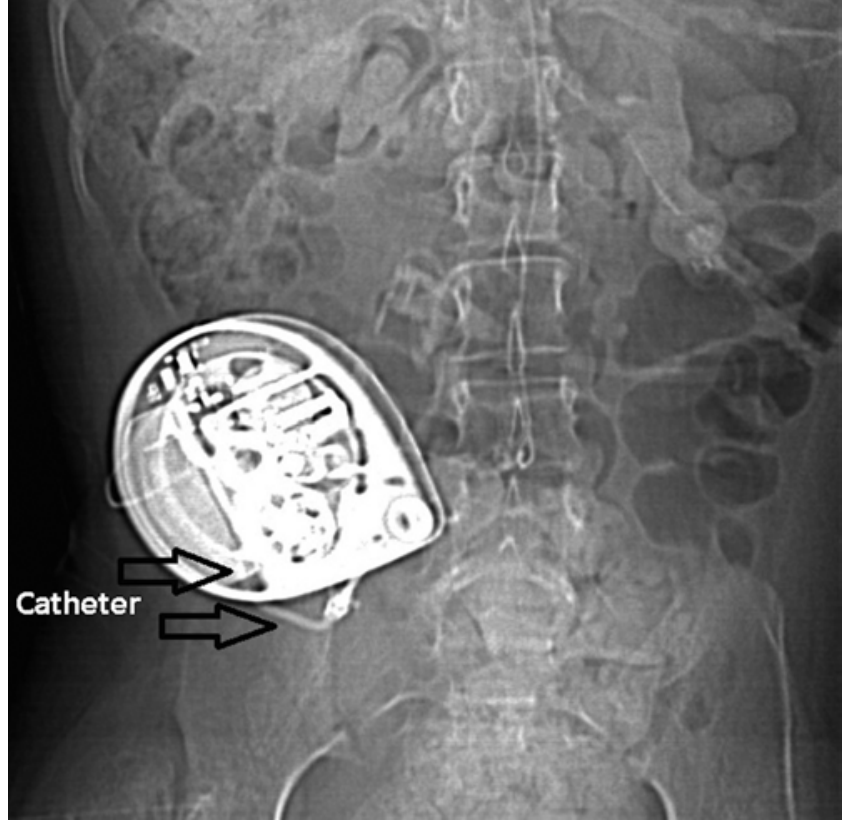

FIG. 4. Preoperative KUB radiograph obtained on August 15, 2014, before revision of the pump catheter, suggesting that the catheter is now anterior to the abdominal pump traversing the refill port.

chance of the catheter slipping out from behind the pump and ending up anterior to the pump. Li et al. emphasized minimizing the length of the catheter outside of the spine as a means of decreasing the likelihood of catheter movement. ${ }^{28}$ Less tubing can lead to an increased likelihood of the catheter slipping out of the intrathecal space as the child grows. However, this must be balanced against the increased risk for catheter migration in the setting of excessive intraabdominal tubing. We believe that our report adds to the existing literature on the complications of intrathecal baclofen pumps, which can aid physicians in optimizing treatment plans for patients who are treated using these pumps by making them aware of potential complications.

\section{Acknowledgment}

We thank Sara Simmons for her assistance in the preparation of this paper.

\section{References}

1. Albright AL, Ferson SS: Intraventricular baclofen for dystonia: techniques and outcomes. Clinical article. J Neurosurg Pediatr 3:11-14, 2009

2. Albright AL, Gilmartin R, Swift D, Krach LE, Ivanhoe CB, McLaughlin JF: Long-term intrathecal baclofen therapy for severe spasticity of cerebral origin. J Neurosurg 98:291295, 2003

3. Alden TD, Lytle RA, Park TS, Noetzel MJ, Ojemann JG: Intrathecal baclofen withdrawal: a case report and review of the literature. Childs Nerv Syst 18:522-525, 2002

4. Awaad Y, Rizk T, Siddiqui I, Roosen N, McIntosh K, Waines GM: Complications of intrathecal baclofen pump: prevention and cure. ISRN Neurol 2012:575168, 2012

5. Awaad Y, Tayem H, Munoz S, Ham S, Michon AM, Awaad $\mathrm{R}$ : Functional assessment following intrathecal baclofen therapy in children with spastic cerebral palsy. J Child Neurol 18:26-34, 2003
6. Bellinger A, Siriwetchadarak R, Rosenquist R, Greenlee JD: Prevention of intrathecal baclofen withdrawal syndrome: successful use of a temporary intrathecal catheter. Reg Anesth Pain Med 34:600-602, 2009

7. Borowski A, Littleton AG, Borkhuu B, Presedo A, Shah S, Dabney KW, et al: Complications of intrathecal baclofen pump therapy in pediatric patients. J Pediatr Orthop 30:76-81, 2010

8. Campbell WM, Ferrel A, McLaughlin JF, Grant GA, Loeser JD, Graubert C, et al: Long-term safety and efficacy of continuous intrathecal baclofen. Dev Med Child Neurol 44:660-665, 2002

9. Coffey JR, Cahill D, Steers W, Park TS, Ordia J, Meythaler J, et al: Intrathecal baclofen for intractable spasticity of spinal origin: results of a long-term multicenter study. J Neurosurg 78:226-232, 1993

10. Coffey RJ, Edgar TS, Francisco GE, Graziani V, Meythaler JM, Ridgely PM, et al: Abrupt withdrawal from intrathecal baclofen: recognition and management of a potentially lifethreatening syndrome. Arch Phys Med Rehabil 83:735-741, 2002

11. Dario A, Tomei G: A benefit-risk assessment of baclofen in severe spinal spasticity. Drug Saf 27:799-818, 2004

12. Dickerman RD, Schneider SJ: Recurrent intrathecal baclofen pump catheter leakage: A surgical observation with recommendations. J Pediatr Surg 37:E17, 2002

13. Dickerman RD, Stevens QE, Schneider SJ: The role of surgical placement and pump orientation in intrathecal pump system failure: a technical report. Pediatr Neurosurg 38:107-109, 2003

14. Douglas AF, Weiner HL, Schwartz DR: Prolonged intrathecal baclofen withdrawal syndrome. Case report and discussion of current therapeutic management. J Neurosurg 102:1133-1136, 2005

15. Dzitoyeva S, Dimitrijevic N, Manev H: Gamma-aminobutyric acid $B$ receptor 1 mediates behavior-impairing actions of alcohol in Drosophila: adult RNA interference and pharmacological evidence. Proc Natl Acad Sci U S A 100:54855490,2003

16. Fjelstad AB, Hommelstad J, Sorteberg A: Infections related to intrathecal baclofen therapy in children and adults: frequency and risk factors. J Neurosurg Pediatr 4:487-493, 2009

17. Gaillard JM: Comparison of two muscle relaxant drugs on human sleep: diazepam and parachlorophenylgaba. Acta Psychiatr Belg 77:410-425, 1977

18. Ghosh D, Mainali G, Khera J, Luciano M: Complications of intrathecal baclofen pumps in children: experience from a tertiary care center. Pediatr Neurosurg 49:138-144, 2013

19. Gooch JL, Oberg WA, Grams B, Ward LA, Walker ML: Complications of intrathecal baclofen pumps in children. Pediatr Neurosurg 39:1-6, 2003

20. Greenberg MI, Hendrickson RG: Baclofen withdrawal following removal of an intrathecal baclofen pump despite oral baclofen replacement. J Toxicol Clin Toxicol 41:83-85, 2003

21. Hansen CR, Gooch JL, Such-Neibar T: Prolonged, severe intrathecal baclofen withdrawal syndrome: a case report. Arch Phys Med Rehabil 88:1468-1471, 2007

22. Haranhalli N, Anand D, Wisoff JH, Harter DH, Weiner HL, Blate M, et al: Intrathecal baclofen therapy: complication avoidance and management. Childs Nerv Syst 27:421-427, 2011

23. Hoving MA, Evers SM, Ament AJ, van Raak EP, Vles JS: Intrathecal baclofen therapy in children with intractable spastic cerebral palsy: a cost-effectiveness analysis. Dev Med Child Neurol 50:450-455, 2008

24. Hoving MA, van Raak EP, Spincemaille GH, Palmans LJ, Becher JG, Vles JS: Efficacy of intrathecal baclofen ther- 
apy in children with intractable spastic cerebral palsy: a randomised controlled trial. Eur J Paediatr Neurol 13:240_ 246, 2009

25. Kao LW, Amin Y, Kirk MA, Turner MS: Intrathecal baclofen withdrawal mimicking sepsis. J Emerg Med 24:423-427, 2003

26. Korenkov AI, Niendorf WR, Darwish N, Glaeser E, Gaab MR: Continuous intrathecal infusion of baclofen in patients with spasticity caused by spinal cord injuries. Neurosurg Rev 25:228-230, 2002

27. Leo RJ, Baer D: Delirium associated with baclofen withdrawal: a review of common presentations and management strategies. Psychosomatics 46:503-507, 2005

28. Li TC, Chen MH, Huang JS, Chan JY, Liu YK, Chen MH: Catheter migration after implantation of an intrathecal baclofen infusion pump for severe spasticity: a case report. Kaohsiung J Med Sci 24:492-497, 2008

29. Meythaler JM, Roper JF, Brunner RC: Cyproheptadine for intrathecal baclofen withdrawal. Arch Phys Med Rehabil 84:638-642, 2003

30. Mezler M, Müller T, Raming K: Cloning and functional expression of GABA(B) receptors from Drosophila. Eur J Neurosci 13:477-486, 2001

31. Miracle AC, Fox MA, Ayyangar RN, Vyas A, Mukherji SK, Quint DJ: Imaging evaluation of intrathecal baclofen pumpcatheter systems. AJNR Am J Neuroradiol 32:1158-1164, 2011

32. Mohammed I, Hussain A: Intrathecal baclofen withdrawal syndrome- a life-threatening complication of baclofen pump: a case report. BMC Clin Pharmacol 4:6, 2004

33. Motta F, Buonaguro V, Stignani C: The use of intrathecal baclofen pump implants in children and adolescents: safety and complications in 200 consecutive cases. J Neurosurg 107 (1 Suppl):32-35, 2007

34. Penn RD: Intrathecal baclofen for spasticity of spinal origin: seven years of experience. J Neurosurg 77:236-240, 1992

35. Penn RD, York MM, Paice JA: Catheter systems for intrathecal drug delivery. J Neurosurg 83:215-217, 1995

36. Reeves RK, Stolp-Smith KA, Christopherson MW: Hyperthermia, rhabdomyolysis, and disseminated intravascular coagulation associated with baclofen pump catheter failure. Arch Phys Med Rehabil 79:353-356, 1998

37. Richard I, Menei P: Intrathecal baclofen in the treatment of spasticity, dystonia and vegetative disorders. Acta Neurochir Suppl 97:213-218, 2007

38. Ross JC, Cook AM, Stewart GL, Fahy BG: Acute intrathecal baclofen withdrawal: a brief review of treatment options. Neurocrit Care 14:103-108, 2011
39. Salazar ML, Eiland LS: Intrathecal baclofen withdrawal resembling serotonin syndrome in an adolescent boy with cerebral palsy. Pediatr Emerg Care 24:691-693, 2008

40. Siegfried RN, Jacobson L, Chabal C: Development of an acute withdrawal syndrome following the cessation of intrathecal baclofen in a patient with spasticity. Anesthesiology 77:1048-1050, 1992

41. Smith TR, Mithal DS, Park A, Bohnen A, Adel J, Rosenow JM: Emergent intrathecal baclofen withdrawal after pseudomeningocele aspiration. Pain Physician 16:E113-E118, 2013

42. Taira T, Ueta T, Katayama Y, Kimizuka M, Nemoto A, Mizusawa H, et al: Rate of complications among the recipients of intrathecal baclofen pump in Japan: a multicenter study. Neuromodulation 16:266-272, 2013

43. Van Schaeybroeck P, Nuttin B, Lagae L, Schrijvers E, Borghgraef C, Feys P: Intrathecal baclofen for intractable cerebral spasticity: a prospective placebo-controlled, doubleblind study. Neurosurgery 46:603-612, 2000

44. Vender JR, Hester S, Waller JL, Rekito A, Lee MR: Identification and management of intrathecal baclofen pump complications: a comparison of pediatric and adult patients. J Neurosurg 104 (1 Suppl):9-15, 2006

45. Ward A, Hayden S, Dexter M, Scheinberg A: Continuous intrathecal baclofen for children with spasticity and/or dystonia: Goal attainment and complications associated with treatment. J Paediatr Child Health 45:720-726, 2009

46. Watve SV, Sivan M, Raza WA, Jamil FF: Management of acute overdose or withdrawal state in intrathecal baclofen therapy. Spinal Cord 50:107-111, 2012

47. Zuckerbraun NS, Ferson SS, Albright AL, Vogeley E: Intrathecal baclofen withdrawal: emergent recognition and management. Pediatr Emerg Care 20:759-764, 2004

\section{Author Contributions}

Conception and design: Dastgir, Ranalli, Aldana. Drafting the article: Dastgir. Critically revising the article: Dastgir, Ranalli, Aldana. Reviewed submitted version of manuscript: all authors. Approved the final version of the manuscript on behalf of all authors: Dastgir.

\section{Correspondence}

Amer Dastgir, Lucy Gooding Pediatric Neurosurgery Center, Wolfson Children's Hospital, 836 Prudential Dr., Ste. 1205, Jacksonville, FL 32207. email: amerdastgirmd@hotmail.com. 